\title{
Dilemas e Desafios no aleitamento materno exclusivo - estudo reflexivo
}

\author{
Dilemmas and Challenges in exclusive breastfeeding - reflective study
}

Dilemas y desafíos en la lactancia materna exclusiva - estudio reflexivo

\section{Beatriz Camilo Lima $^{1 *}$, Marilei de Melo Tavares ${ }^{2}$, Alessandra da Silva Souza ${ }^{3}$, Geísa Sereno Velloso da Silva ${ }^{4}$, Lilia Marques Simões Rodrigues ${ }^{5}$, Elisangêla do Nascimento Fernandes Gomes ${ }^{6}$}

Como citar esse artigo. Lima, $\mathrm{BC}$; Tavares; MM; Souza, AS; da SIlva, GSV; Rodrigues, LMS; Gomes, ENF. Dilemas e Desafios no aleitamento materno exclusivo - estudo reflexivo. Revista Pró-UniverSUS. 2021 Jul./Dez.; 12 (2)SUPLEMENTO: 58 - 61

\section{Resumo}

Este estudo teve como objetivo refletir sobre os desafios e dificuldades encontrados por puérperas durante a amamentação exclusiva de seus lactentes. Trata-se de um estudo reflexivo a partir de uma revisão da literatura sobre os desafios e dificuldades para amamentar. Os resultados apontam como um dos maiores desafios a pega correta, a produção suficiente de leite e a grande demanda de tempo e dedicação; e dificuldades, a falta de informação e de uma rede de apoio eficiente, complicações como dor, fissuras no mamilo, ingurgitamento, desconforto e fatores oriundos do bebê como rejeitar a mama, ficar sonolento e não mamar ou até mesmo mamar várias vezes levando a puérpera a exaustão. Em síntese a enfermagem tem um papel fundamental para a promoção do aleitamento materno exclusivo. Importante prestar orientações, esclarecer possíveis dúvidas, ensinar a pega correta a fim de evitar complicações. Por fim, orientar para que a família forme uma rede de apoio de qualidade para que a mulher receba a ajuda que necessária.

Palavras-chave: Amamentação; Enfermagem; Lactentes; Pega Correta; Puérperas; Rede de Apoioe.

\begin{abstract}
This study aimed to reflect on the challenges and difficulties encountered by puerperal women during exclusive breastfeeding of their infants. This is a reflective study based on a literature review on the challenges and difficulties of breastfeeding. The results point as one of the biggest challenges the correct handle, the sufficient milk production and the great demand of time and dedication; and difficulties, lack of information and an efficient support network, complications such as pain, nipple cracks, engorgement, discomfort and factors originating from the baby, such as rejecting the breast, getting drowsy and not breastfeeding or even breastfeeding several times leading to the puerperal woman exhaustion. In summary, nursing has a fundamental role in promoting exclusive breastfeeding. It is important to provide guidance, clarify possible doubts, teach the correct handle in order to avoid complications. Finally, guide the family to form a quality support network so that the woman receives the help she needs.
\end{abstract}

Keywords: Breast-Feeding; Nursing; Infants; Correct Handle; Puerperal Women; Support Network.

${ }^{1 *}$ Acadêmica da graduação em enfermagem pela Universidade de Vassouras, RJ, Brasil. Email: biacamilo76@gmail.com ORCID: https://orcid.org/0000-0002-0565-8587. ${ }^{2}$ Pós-Doutora pela UERJ. Docente permanente do Programa de Pós-graduação em Enfermagem - MPES/UFF. Líder do Núcleo de Pesquisa Trabalho, Meio Ambiente, Arte e Emoções em saúde (Nupetmae-CNPq). Docente do Curso de Enfermagem da Universidade de Vassouras. Vassouras, RJ, Brasil. E-mail: marileimts@hotmail.com ORCID: http://orcid. org/0000-0002-3276-0026.

${ }^{3}$ Mestre. Professor do Curso de Enfermagem, Universidade de Vassouras. RJ, Brasil. Email: alesouza22@yahoo.com.br ORCID: https://orcid.org/0000-0002-9009-9774.

${ }^{4}$ Mestre. Professor do Curso de Enfermagem, Universidade de Vassouras. RJ, Brasil. Email: geisa.velloso@hotmail.com ORCID: https://orcid.org/0000-0003-0304-8010.

${ }^{5}$ Mestre. Docente do Curso de Enfermagem da Universidade de Vassouras, Vassouras, RJ, Brasil. Email: liliasrodrigues21@gmail.com ORCID: https://orcid.org/0000-0003-29796316.

${ }^{6}$ Mestre. Docente do Curso de Enfermagem, Universidade de Vassouras. RJ, Brasil. Email: elisangelavass@yahoo.com.br ORCID: https://orcid.org/0000-0001-8432-4157.

* Email de correspondencia: biacamilo76@gmail.com

Recebido em: 21/01/21. Aceito em: 08/06/21. 


\section{Resumen}

Este estudio tuvo como objetivo reflexionar sobre los desafíos y dificultades que enfrentan las puérperas durante la lactancia materna exclusiva de sus bebés. Se trata de un estudio reflexivo basado en una revisión de la literatura sobre los desafíos y dificultades de la lactancia materna. Los resultados apuntan como uno de los mayores retos el manejo correcto, la producción de leche suficiente y la gran exigencia de tiempo y dedicación; y dificultades, falta de información y de una red de apoyo eficiente, complicaciones como dolor, grietas en el pezón, congestión, malestar y factores originados por el bebé, como rechazar el pecho, adormecerse y no amamantar o incluso amamantar varias veces que conducen al parto. agotamiento. En resumen, la enfermería tiene un papel fundamental en la promoción de la lactancia materna exclusiva. Es importante orientar, aclarar posibles dudas, enseñar el manejo correcto para evitar complicaciones. Finalmente, orientar a la familia a formar una red de apoyo de calidad para que la mujer reciba la ayuda que necesita.

Palabras clave: Amamantamiento; Enfermería; Infantes; Mango Correcto; Mujeres Puerperales; Red de Soporte.

\section{Introdução}

A Organização Mundial da Saúde (OMS) e o Ministério da Saúde (MS) recomendam Aleitamento Materno Exclusivo (AME) por seis meses e complementado até os dois anos ou mais. Não há benefícios em se iniciar os alimentos complementares antes dos seis meses, podendo, inclusive, haver prejuízos à saúde da criança, como: maior número de episódios de diarreia, maior número de hospitalizações por doença respiratória, risco de desnutrição se os alimentos introduzidos forem nutricionalmente inferiores ao leite materno, menor absorção de nutrientes importantes do leite materno, como o ferro e o zinco, menor eficácia da lactação como método anticoncepcional e menor duração do aleitamento materno. No segundo ano de vida, o leite materno continua sendo importante fonte de nutrientes e protegendo contra doenças infecciosas. Uma análise de estudos realizados em três continentes concluiu que quando as crianças não eram amamentadas no segundo ano de vida elas tinham uma chance quase duas vezes maior de morrer por doença infecciosa quando comparadas com crianças amamentadas ${ }^{1}$.

Amamentar é muito mais do que nutrir a criança. É um processo que envolve interação profunda entre mãe e filho, com repercussões no estado nutricional da criança, em sua habilidade de se defender de infecções, em sua fisiologia e no seu desenvolvimento cognitivo e emocional, além de ter implicações na saúde física e psíquica da mãe $e^{2,3,4}$. No entanto, muitos são os desafios e dificuldades encontradas pelas puérperas nesta fase tão desafiadora de suas vidas e para que essas mães consigam amamentar exclusivamente é muito importante se atentar para fatores que venham contribuir com isso, como favorecer a interação mãe-bebê, e uma das formas é com a criação de um vínculo que é formado durante a mamada que aumenta a duração do $\mathrm{AME}^{5}$.

Muito embora o ato de amamentar se constitua uma característica humana, $\mathrm{o}$ ato de amamentar figura-se como prática social estruturada e complexa. É produzida e reproduzida a partir das relações em que a mulher se insere, o que pode ocasionar obstáculos, dificuldade para amamentar, falta de apoio, dilemas envolvendo o processo de amamentar e trabalhar, dentre outras ${ }^{6}$.

A concepção muitas vezes das mulheres sobre o aleitamento materno reflete em seu modo de agir diante ao gesto de amamentar. Muitas vezes conhecimento e informações sobre amamentação estão relacionados a percepção que tem sobre prevenção e proteção ${ }^{7}$.

O profissional de saúde tem um papel fundamental no processo de amamentar, e para que seja bem-sucedido precisa estar preparado, com embasamento teórico sobre a lactação, bem como com trabalho de promoção e apoio à mãe, tendo um olhar atento, abrangente, sempre levando em consideração os aspectos emocionais, a cultura familiar, a rede social de apoio à mulher, a qual precisa ser protagonista do seu processo de amamentar.

Diante o exposto, considerando a importância de amamentar e todos os benefícios tanto para os bebês quanto para as mães, o presente estudo tem por objetivo refletir sobre os desafios e dificuldades encontrados por puérperas durante a amamentação exclusiva de seus lactentes.

\section{Metodologia}

Trata-se de um estudo reflexivo a partir de revisão de literatura efetuada mediante levantamento bibliográfico. Buscando compreender o comportamento e estudando as particularidades e experiências. como principal finalidade desenvolver, esclarecer ideias para estudos posteriores ${ }^{8}$.

A análise documental foi realizada na Biblioteca Virtual de Saúde (BVS), na base: Lilacs e SciELO. A partir de documentos escritos - artigos científicos referentes aos desafios e dificuldades na amamentação exclusiva, utilizando para busca, os descritores: 
Aleitamento Materno, Dificuldades, Amamentação. E para a análise do material localizado, foram agrupas as informações adquiridas em concordância com o foco/ objetivo do estudo.

\section{Resultados e Discussão}

\section{Principais desafios e dificuldades no decorrer da amamentação exclusiva}

Importante refletir sobre dificuldades e desafios encontrada por puérperas durante o aleitamento, fatores os quais, quando não solucionados interferem no Aleitamento Materno Exclusivo (AME) podendo ocasionar inclusive no desmame precoce.

Estudos apontam que a finalidade de identificar essas questões, este conhecimento é importante, pois poderá direcionar as práticas educativas realizadas por enfermeiros no sentido de minimizar as dificuldades enfrentadas pelas puérperas durante a amamentação, reduzindo os índices do desmame precoce. Acredita-se que o estudo poderá oferecer dados para a reflexão dos profissionais da equipe de enfermagem acerca de suas intervenções frente aos fatores que interferem na prática da amamentação, qualificando o seu fazer ${ }^{4}$.

Considerando a extrema importância do aleitamento materno, a enfermagem tem o papel de incentivar e educar as puérperas para que esse processo se dê de forma satisfatória. E para essas intervenções, existem momentos oportunos, um deles é no pré-natal outro é na internação para o parto, no qual se retoma o que foi dito no pré-natal quanto à lactação. Com as devidas orientações dadas no momento da alta, ressaltando o que foi dito anteriormente, a mulher pode sentir-se com mais segurança, prazer e harmonia para enfrentar as dificuldades enfrentadas no puerpério ${ }^{5}$.

A enfermagem também tem o papel de realizar as orientações prévias ao nascimento, assim como no pós-parto, com os objetivos de preparar a mãe para superar as dificuldades que possam surgir, minimizar as preocupações e fortalecer sua autoconfiança, acreditando que quanto mais instruída sobre o assunto, maior facilidade terá para superar os obstáculos 9 .

Assim, o enfermeiro deve identificar durante o pré-natal os conhecimentos, a experiência prática, as crenças e a vivência social e familiar da gestante com a finalidade de promover educação em saúde para o aleitamento materno, assim como, garantir vigilância e efetividade durante a assistência a nutriz no pósparto $^{10}$.

Após o nascimento do recém-nascido as puérperas se deparam com uma nova fase, extremamente desconhecida e por isso a importância da criação e fortalecimento de sua rede de apoio, seja ela composta pela mãe, por seu parceiro, por quem pertencer a essa nova família. Todos precisam ser incluídos, recebendo as orientações, salientando dúvidas, aprendendo seu papel nesse momento para saber como ajudar, entre outros.

Dentre os desafios encontrados durante a amamentação, os mais comuns são a pega correta, ter uma produção suficiente de leite e a grande demanda de tempo e dedicação. No entanto, eles facilmente podem ser resolvidos com orientação, através de educação permanente tanta com a mãe quanto com a rede de apoio, pois eles também desenvolveram um papel de suma importância garantindo sucesso nessa fase. Uma vez que essa rede de apoio não possui informação, eles exercerão um papel contrário, dificultando o ato de amamentar, pois ao transmitir suas experiências eles também, transmitiram crenças, mitos e tradições enraizados no contexto familiar, os quais, muitas vezes, não possuem comprovação científica e diferem das recomendações atuais.

É preciso também destacar que algumas avós provêm de uma geração que desvalorizava o leite materno e não o considerava como a única fonte de alimento para a criança. Sendo assim, mesmo com boas intenções, algumas vezes, elas podem repassar orientações errôneas, que podem contribuir para o desmame precoce ${ }^{11}$.

Já como dificuldades podemos destacar principalmente os problemas com a mama puerperal, ou seja, o ingurgitamento mamário e as lesões mamilares, que são atribuídos à inadequação da posição para amamentar e/ou à pega do bebê ao seio ${ }^{12}$. Esses problemas com a mama podem comprometer o sucesso do aleitamento materno.

Em relação a pegada correta do bebê no seio. A lactante deve segurar a mama e posicionar o bebê para que ele pegue bem na mama, abrindo bem a boca para pegar quase toda ou toda a região do mamilo e da auréola, obtendo assim uma boa sucção. A mãe deve estar em posição confortável, podendo estar em pé, deitada ou sentada, de maneira que a barriga do bebê esteja junto ao corpo da mãe, facilitando a respiração, sucção e deglutinação durante a amamentação ${ }^{13}$.

A avaliação das dificuldades técnicas da mamada, ainda dentro do ambiente hospitalar, é uma forma simples, sem custos e que não demanda profissional especializado para sua realização, de maneira que poderia ser incorporada aos critérios de alta hospitalar, a fim de identificar e auxiliar os binômios que apresentam algum impedimento no exercício do processo de amamentação, provendo as devidas orientações que retifiquem essas dificuldades e que fortaleçam o vínculo entre mãe-lactente ${ }^{14}$.

Observa-se também que a necessidade de retornar ao trabalho dificulta o êxito do aleitamento já que muitas mulheres trabalham para ajudar nas despesas de 
casa e em muitos outros casos, desempenham o papel de chefes de família. Por conseguinte, muitas retornam com até quatro meses pós-parto ${ }^{2,6}$.

\section{Considerações Finais}

O estudo buscou de uma forma geral evidenciar as principais dificuldades e desafios encontrados pelas puérperas durante a amamentação, fatores os quais em sua maioria interferem no êxito do aleitamento materno exclusivo e levam ao desmame precoce.

Nos mostrou também que a baixa renda das famílias e a necessidade de trabalhar para garantir o sustento se coloca como umas das principais causas para a interrupção do aleitamento, sendo um problema bem mais complexo pra se resolver.

Um outro ponto foi em relação a complicações como dor, fissuras no mamilo e ingurgitamento, no entanto, esses fatores abordados se resolvem facilmente com intervenções de enfermagem eficazes.

Considerando todo estudo conclui-se que os profissionais desempenham um papel de extrema importância no sucesso AME, é necessário um acompanhamento em todos os estágios da gestação ao puerpério para a realização de orientações, esclarecimento de dúvidas, e após o parto a avaliação mais direta da amamentação, a fim de verificar a pega e intervir o mais breve possível se houver necessidade.

Por Fim, compreender a mulher, seus medos e anseios torna-se fundamental traçar medidas interventivas para ajudá-la a ter sucesso na lactação, tendo um momento prazeroso com seu recém-nascido, de troca de carinho, de afeto, de amor, de fortalecimento do vínculo mãe/filho e não de medos e anseios, buscando entender os motivos que levam à interrupção do aleitamento ocasionando o desmame precoce.

\section{Referências}

1. Brasil. Ministério da Saúde. Secretaria de Atenção à Saúde. Departamento de Atenção Básica. Saúde da criança: nutrição infantil: aleitamento materno e alimentação complementar / Ministério da Saúde, Secretaria de Atenção à Saúde, Departamento de Atenção Básica. - Brasília: Editora do Ministério da Saúde, 2009. 112 p. : il. - (Série A. Normas e Manuais Técnicos) (Cadernos de Atenção Básica, n. 23)

2. Vasconcelos TC, Barbosa DJ, Gomes MP. Fatores que interferem no aleitamento materno exclusivo durante os primeiros seis meses de vida do bebê. Revista Pró-UniverSUS. 2020 Jan./Jun.; 11 (1): 80- 87

3. Corrêa, LF; Souza, AS. Percepção de mães primíparas sobre os benefícios da amamentação. Revista Pró-UniverSUS. 2019 Jan./Jun.; 10 (1): 93-96.

4. Urbanetto PDG, Gomes GC, Costa AR, et al. Facilidades e dificuldades encontradas pelas puérperas para amamentar. Rev Fund Care Online. 2018 abr/jun; 10(2):399-405. DOI: http://dx.doi.org/10.9789/2175-5361.2018. v10i2.399-405.

5. Francisquini AR, Higarashi IH, Serafim D, Bercini LO. Orientações recebidas durante a gestação, parto e pós-parto por um grupo de puérperas. Ciênc cuid saúde. 2010;9(4):744-51. Disponível em: http://eduem.uem.br/
ojs/index.php/CiencCuidSaude/article/ viewFile/13826/7193.

6. Tavares MM, Rodrigues, LMS. Desafios da mulher trabalhadora diante amamentação. Revista Pró-UniverSUS, 2010; 1(1), 33-42.

7. Correa LF, Souza AS. Percepção de mães primíparas sobre o benefício da amamentação. Revista Pró-UniverSUS, 2019; 10(1): 93-96.

8. Gil AC. Métodos e técnicas de pesquisa social. 6. ed. São Paulo: Atlas, 2008.

9. Almeida IS, Ribeiro IB, Rodrigues BMRD, Costa CCP, Freitas NS, Vergas EB. Amamentação para mães primíparas: perspectivas e intencionalidades do enfermeiro ao orientar. Cogitare enferm. 2010;15(1):1925. Disponível em: file://D:/Downloads/17139-60052-2- PB\%20(1).pdf

10. Almeida NAM, Fernandes AG, Araújo CG. Aleitamento materno: uma abordagem sobre o papel do enfermeiro no pós-parto. Revista eletr. enferm. 2004;6(3):358-67.

11. Zanin LC, Schacker LC. Avós maternas: incentivadoras da amamentação? Rev conhec online. 2010;1(2):1-13

12. Giugliani ER. Problemas comuns na lactação e seu manejo. J Pediatr (Rio J). 2004;80 Suppl 5:S147-54.

13. Magarotti E, Epifaneo M. Aleitamento materno exclusivo e a escala de autoeficácia na amamentação. Rev Rene., 2014 set-out; 15(5):771-9.

14. Barbosa GEF, Silva VB, Pereira JM, Soares MS, Medeiros FRA, Pereira LB et al. Dificuldades iniciais com a técnica da amamentação e fatores associados a problemas com a mama em puérperas. Rev. paul. pediatr. [Internet]. 2017 Set 35(3): 265-272. 